\title{
Sociodemographic and Hematologic Profile of Breast Cancer Patients Attending a Tertiary Care Teaching Hospital in Ethiopia: Case Control Study
}

Fatuma Hassen Dejene ( $\sim$ fatumahassen2000@yahoo.com )

Addis Ababa University College of Health Sciences

Fikre Enqusilassie Gashe

Addis Ababa University School of Public Health

Ahmed Ali Ahmed

Addis Ababa University School of Public Health

Adamu Addise Nuramo

Addis Ababa University School of Public Health

Girma Taye aweke

Addis Ababa University School of Public Health

Mathewos Assefa Woldegeorgis

Addis Ababa University School of Medicine

Aster Tsegaye Abebe

Addis Ababa University School of Public Health

Research article

Keywords: Breast Cancer, Hematological parameters, Socio-demographic factors, Ethiopia

Posted Date: September 2nd, 2020

DOl: https://doi.org/10.21203/rs.3.rs-60844/v1

License: (c) (1) This work is licensed under a Creative Commons Attribution 4.0 International License.

Read Full License 


\section{Abstract}

Background: Breast cancer is among the leading causes of cancer death in women. Different sociodemographic factors have impact on early diagnosis and treatment of breast cancer. Hematological abnormalities are also some of the conditions to be monitored during diagnosis and treatment of breast cancer.

Objective: To describe socio demographic and hematologic profile of patients with breast cancer at Tikur Anbessa Specialized Hospital.

Methods: Case control study was conducted from May 2018 to June 2019. A total of 230 cases and 230 controls participated in the study. Descriptive analysis was made to assess the socio demographic characteristics. Blood samples for hematological parameters were analyzed, using SYSMEXKX21N hematology analyzer. Independent student t- test was performed to compare the mean hematological parameters of cases and controls.

Results: The mean age was $42.8 \pm 12.1$ and $39.3 \pm 11.1$ years for cases and controls, respectively. One hundred $(43 \%)$ of cases and $34(14.8 \%)$ of controls were illiterate. Moreover, $175(76.1 \%)$ of cases and 155 (67.4\%) of controls were married. The mean value of Hemoglobin, Red Blood cell, Packed Cell Volume $\left(13.1 \pm 1.6 \mathrm{~g} / \mathrm{dl}, 4.6 \pm 0.54 / 10^{12} / \mathrm{L}, 38.7 \pm 4.5 \%\right.$, respectively) of cases were significantly lower than the controls $\left(14.0 \pm 1.3 \mathrm{~g} / \mathrm{dl}, 4.8 \pm 0.47 / 10^{12} / \mathrm{L}, 40.5 \pm 3.5 \%\right.$ respectively). The mean platelet and total WBC count were 323.4 $\pm 108.1 \times 10^{9} / \mathrm{L}$ and $7.1 \pm 2.8 \times 10^{9} / \mathrm{L}$ for cases and $282.0 \pm 70.0 \times 10^{9} / \mathrm{L}$, and $7.1 \pm 2.4 \times 10^{9} / \mathrm{L}$ for controls respectively. In addition, $20.4 \%$ of cases and $5.6 \%$ of controls were anemic based on their hemoglobin value.

Conclusion and recommendations: The majority of breast cancer cases were less than 40 years of age and illiterate. Most of the RBC parameters of cases were significantly lower than the controls. Therefore, attention should be given to those with the designated hematologic abnormalities.

\section{Background}

Breast cancer is the leading cause of cancer deaths in women, accounting for $15.0 \%$ of the deaths (1). Even though there are significant improvements in breast cancer prognosis and survival, it is still the leading cause of mortality in low- and middle-income countries (1-3). In most African countries, cancer control programs and the provision of early detection and treatment services are limited, despite the increasing burden (4).

\section{Socio demographic factors affecting Breast Cancer}

Socio-demographic factors are reckoned to be associated with breast cancer. Based on the findings of systematic review and meta-analysis in Europe, higher socioeconomic status of women was significantly 
associated with higher breast cancer incidence (5). In a study conducted in Baghdad on 250 female breast cancer patients, their ages ranged between 42 and 73 years, with a mean \pm SD of $56 \pm 6$ years (6). Those younger than 50 years constituted $19.6 \%$ of the sample, while those older than 59 years made $22 \%$ of the study participants. Majority, $54.8 \%$ of them completed their secondary school education. Furthermore, $60.8 \%$ were married, $44 \%$ were unemployed and $25.2 \%$ were rural residents. . According to a study done in Iraq, the mean age at the presentation was $51 \pm 10.6$ years; patients less than 50 were $46.8 \%$ (7). Overall, $88 \%$ were married, $22.4 \%$ were illiterate and $19.2 \%$ graduated from universities. A WHO survey which was done on socio-economic and health access determinants of breast and cervical cancer screening in Low-Income Countries found that significant determinants of cancer screening were household socio economic status, rural residence, country health expenditure, as well as healthcare access (8). A study conducted in Nigeria also indicated that, socio-demographic factors increased risk of late presentation (9).

Ethiopia is undergoing a rapid economic transformation that has increasingly been accompanied by changes in the dietary and lifestyle behaviors of the population, contributing to rising risks of preventable chronic illnesses. The double burden of communicable and chronic diseases is a challenge to the health as well as to the national socio economic development. Chronic non communicable diseases are posing a formidable social and economic burden on individuals, families and the nation at large (10). Breast cancer trend is increasing and it is the most prevalent type of cancer $(11,12)$. In general, cancer accounts for about $5.8 \%$ of the total national mortality in the country and breast cancer is the most prevalent cancer (13).

\section{Hematological profile and breast cancer}

Hematological abnormalities are common features to be considered in breast cancer patients. Those parameters could be used as one of the important biochemical tools in the diagnosis of additional comorbidities and treatment monitoring in breast cancer patients. They are cost effective and can be easily examined in less complex laboratories that do not have access to sophisticated technology for demonstration of more reliable cancer markers (14). Studies indicate hematological parameters as important investigations that are useful prognostic factors for evaluating the accuracy of risk stratification in breast cancer patients $(15,16)$. For example, a study done in south western Nigeria showed that HB, PCV, RBC and WBC were significantly lower in patients compared to controls (16). Another study done in Nigeria also showed that mean $\mathrm{MCV}, \mathrm{MCH}, \mathrm{MCHC}$ in cases were lower than in controls (17). Be careful of your spacing.

Mean PCV, RBCs and WBCs, platelet values were significantly lower in patients compared to the controls based on the study done in Iraq (18). Another study from Malaysia revealed significant decrease of hemoglobin among $22 \%$ of breast cancer patients (19). Based on study in Ethiopia, there is poor community awareness towards breast cancer (20). Studies also indicated that 80 to $90 \%$ of patients already suffer from advanced and incurable cancers at the time of diagnosis (20-22). Socio-demographic factors are the determinants of health-related behavior. It is also indicated that socio-demographic 
factors may have effect on late presentation and contribute to treatment delay, neglecting symptoms and illnesses as well as late notifications to clinicians (9).

Since breast cancer is associated with lifestyle, it is important to investigate and understand various socio-demographic elements of patients with the disease. This study may help to identify the target group for counseling, and awareness creation, depending on their needs in the general population. Even though, breast cancer incidence has increased rapidly in Ethiopia (13), there is still lack of adequate studies that investigated socio demographic and hematological profile of breast cancer patients in order to design and implement strategies which can be helpful for prevention and improve the outcome of patients. It is important to assess hematological status of breast cancer patients at regular intervals during different stages of treatment in order to determine their diagnostic and prognostic values, which can help for improved management. Therefore, this study was aimed to describe socio demographic and hematologic profile of patients with breast cancer at Tikur Anbessa Specialized Hospital.

\section{Materials And Methods}

\section{Study design and period}

Facility based case control study was conducted between May 2018 to June 2019 in Addis Ababa at Tikur Anbesa Specialized Hospital (TASH) Oncology Department. Cases and controls were matched based on residence.

\section{Eligibility criteria}

All newly diagnosed breast cancer patients with confirmed histology result, no observable mental disorders, no history of chronic disease and aged 18years and above were included in the study. Regarding controls, individuals free from breast mass after physical examination, non-pregnant women and women who were not on menstruation period and individuals who had no biological relationship with selected cases were included.

\section{Sampling and sample Size determination}

Since there was only one referral center for cancer treatment during the study period, purposive sampling technique was used to select the study area (TASH). Convenient sampling technique was used to select study participants. A total of 460 participants (230 cases and 230 controls) participated in this study.

\section{Data collection procedure}

Informed consent was obtained from each study participant prior to data collection. Participants were interviewed in a convenient place to maintain privacy and confidentiality. Hematological testes were 
routinely done for treatment of each breast cancer case before any kind of treatment; hence, the result of each study participant was taken from their records. For controls, breast physical examination was conducted by oncology residents in order to select eligible controls. If the control was eligible for the study, interview was conducted by experienced nurses. At the end of each interview, blood specimen were collected from each control by experienced laboratory technologist and analyzed using SysmexKX $-21 \mathrm{~N}$ hematology analyzer at TASH Laboratory.

\section{Data analysis and management}

Data analysis was done using SPSS Software, version 20. Then, descriptive analysis was made in order to assess the socio-demographic characteristics of cases and controls. Independent student t- test was used to compare the mean $\underline{ \pm}$ standard deviation of different hematological parameters among cases and controls. $P$ value less than 0.05 were considered as statistically significant.

In order to assess presence of selected hematologic abnormalities, the reference range was taken from WHO and from the output of hematology analyzer. Regarding anemia, WHO 2011 hemoglobin (HB) concentration for the diagnosis of anemia and assessment of severity was used. As per this assessment, if $\mathrm{HB}$ concentration is $\geq 12 \mathrm{gm} / \mathrm{dl}$, there is no anemia, mild anemia when $\mathrm{HB}$ is $10.9-11.0 \mathrm{gm} / \mathrm{dl}$, moderate anemia when HB is $8.0-10.9 \mathrm{gm} / \mathrm{dl}$ and severe anemia when $\mathrm{HB}$ is less than $8 \mathrm{gm} / \mathrm{dl}$. In addition, anemia was also further characterized as microcytic and macrocytic anemia based on MCV values. Similarly, anemia was also characterized as hypochromic and normochromic anemia, based on MCHC values based on the reference range of CBC SYSMEX KX - 21N. In addition, in order to characterize the level of leucocyte and platelet, the reference was based on the reference range established by the CBC SYSMEX $K X-21 \mathrm{~N}$ hematology analyzer. Based on the analyzer, the reference range of WBC count was $3.7-10.4$ $\times 10^{9} / \mathrm{L}$. When WBC count was less than the lower range $\left(3.7 \times 10^{9} / \mathrm{L}\right)$, it was characterized as leucopenia, whereas when the value was greater than the upper range $\left(10.4 \times 10^{9} / \mathrm{L}\right)$, it was characterized as lecocytosis. Regarding the platelet count, the established reference range was $163-337 \times 10^{9} / \mathrm{L}$. Similarly, if the platelet count was less than the lower range $\left(140 \times 10^{9} / \mathrm{L}\right)$, it was characterized as thrombocytopenia, whereas when the value was greater than the upper range ( $\left.385 \times 10^{9} / \mathrm{L}\right)$, it was characterized as thrombocytosis.

\section{Data Quality Control and Assurance}

The data collection tools were prepared in English and translated to the local language in order to facilitate understanding of the study participants. The data collection tools were pretested on $5 \%$ of breast cancer patients not included in the study. Daily supervision was made on all questioners collected on each day. Regarding quality assurance of laboratory tests, collected specimens were analyzed on the same day of sample collection. Quality control samples were analyzed before testing actual patient samples, in order to check for the performance of testing reagent and hematology analyzer. 


\section{Ethical consideration}

Ethical approval was obtained from the School of Public Health Research Ethical Review Committee, and it was also approved by Institutional Review Board of the College of Health Sciences of the Addis Ababa University. Written consent was obtained from each of the respondents after the purpose of the study was explained. During breast physical examination for screening of controls, participants who had breast mass were consulted by physicians and their results were given for free in order to get early diagnosis and treatment. Confidentiality and privacy was maintained throughout the study.

\section{Results}

\section{Sociodemographic characteristics of study participants}

In this study, a total of 230 breast cancer cases and 230 healthy controls participated. $70.9 \%$ of the cases and $75,7 \%$ of the controls were urban dwellers. The mean age of study participants were $42.83 \pm 12.06$ and $39.33 \pm 11.14$ years for cases and controls, respectively. More than half $(54.3 \%)$ of cases and $62.2 \%$ controls were less than 40 years old (Table1). By religion, $67.4 \%$ of cases and $59.1 \%$ of controls were followers of the Ethiopian Orthodox Church. Regarding marital status, $76.1 \%$ of cases and $67.4 \%$ of controls were married. However, nearly half (43.5\%) of the cases were illiterate, while $30 \%$ of controls have attained secondary education. More than half (69.6\%) of the cases and $43.1 \%$ of controls were housewives Regarding income, even though limited number of study participants responded about their income, 37, (34.3\%) of the cases had lessthan 1000 Ethiopian Birr per month. However, 47, (37\%) of controls had more-than3000 Ethiopian Birr income per month (Table 1).

\section{Hematologic profile of breast cancer cases and controls}

\section{Hemoglobin, Red Blood Cells platelet count and Packed Cell Volume}

The overall mean values with standard deviation of Hemoglobin (HB), Red Blood cell (RBC), Packed Cell Volume (PCV), of cases were $\left(13.1 \pm 1.6 \mathrm{~g} / \mathrm{dl}, 4.6 \pm 0.53 \times 10^{12} / \mathrm{Land} 38.7 \pm 4.5 \%\right.$, respectively and those values for controls were $\left(14.0 \pm 1.3 \mathrm{~g} / \mathrm{dl}, 4.8 \pm 0.4710^{12} / \mathrm{L}, 40.5 \pm 3.5 \%\right.$ respectively (Table 2$)$. On the other hand, mean platelet count for the cases and controls were $\left(323.4 \pm 108.1 \times 10^{9} \mathrm{~L}\right)$ and $\left(282.0 \pm 70.0 \times 10^{9} \mathrm{~L}\right)$ respectively. As indicated in table 2 , the $P$ value is $<0.05$ for the above parameters.

\section{Red cell induces}

The overall $\mathrm{MCV}, \mathrm{MCH}$ and $\mathrm{MCHC}$ values of the cases and controls were $(84.3 \pm 8.1 \mathrm{fl}, 29.0 \pm 4.2 \mathrm{pg}$, and $33.6 \pm 1.7 \%$, ) and $(85.7 \pm 6.0 \mathrm{fl}, 29.5 \pm 2.4 \mathrm{pg}, 34.2 \pm 2.5 \%)$ respectively (Table 3$)$. As indicated in table 3 , thee was significance difference of MCV and MCHC values of cases and controls, $(P<0.05)$. on the other hand, $P$ value was 0.153 for $\mathrm{MCH}$ value.

\section{Total WBC and WBC differential parameters}


In this study, the mean value of total WBC was7.1 \pm 2.8 and $7.1 \pm 2.4 \times 10^{9} / \mathrm{L}$ for cases and controls respectively.which did not show statistically significant difference $(P=0.332)$ between the two groups. The mean neutrophil, lymphocyte, monocyte and eosinophil counts $(55.19 \pm 13.96 \%, 29.67 \pm 11.21 \%$, $10.14 \pm 5.54 \%$, and $4.05 \pm 4.65 \%$, respectively) of the cases were,significantly higher than the controls $(36.39 \pm 19.27 \%, 24.58 \pm 8.40 \%, 5.51 \pm 2.08 \%$, and $2.80 \pm 3.88 \%)$, respectively.

\section{Characterization of some selected hematologic parameters}

In this study, $20.4 \%$ of cases and $5.6 \%$ of controls were anemic based on their hemoglobin value (Table). Based on severity of anemia, majority, $27(11.7 \%)$ of cases and $4(1.7 \%)$ controls were moderately anemic. On the other hand, $20,(8.7 \%)$ of cases and $8,(3.5 \%)$ of controls were mild anemic, $(P=0.0001)$. (Table 4).

Out of the total anemic study participants, $20,(33.3 \%)$ of cases and $8(13.3 \%)$ of controls were mild anemic. $27(45 \%)$ of cases and $4(6.7 \%)$ of controls were moderately anemic and only one control $(1.7 \%)$ were severely anemic.(Figure 1 ).

Regarding characterizing the anemia according to the size of red blood cell and hemoglobin concentration, microcytic anemia was found among $64(28.2 \%)$ of the cases and $42,(18,4 \%)$ of controls. On the other hand, macrocytic anemia was found among $2(0.9 \%)$ of cases and $3(1.3 \%)$ of controls. Similarly, $15(6.6 \%)$ of cases and 8 (3.5\%) of controls had hypochromic anemia. In addition, $23,(10.5 \%)$ of cases and 7, (3\%) of controls were with normocytic anemia, $27,(11.7 \%)$ of cases and $9,(3.9 \%)$ of controls with normochromic anemia and $9,(3.9 \%)$ of cases and $4(1.7 \%)$ of controls with microcytic hypochromic anemia (Table 4). Regarding their leucocyte, leucopenia is insignificant difference among cases and controls. Lecucytosis is also more or less similar. Similarly, thrombocytopenia is not observed among cases and controls. However, thrombocytosis was found among $54,(23.5 \%)$ of the cases and $18,(7.8 \%)$ of controls, $(P=0.0001)$. (Table 4$)$.

The finding also indicated that $16(7.0 \%)$ of cases and $1(0.4 \%)$ of controls were both anemic and with thrombocytosis, $(P=0.0001)$. Similarly, $(2.2 \%)$ of cases and only none $(0.0 \%)$ of controls had the triple burden of anemia, lecocytosis and thrombocytosis. There was no significant difference among cases and controls for hypochromic anemia, microcytic hypochromic anemia and Leucopenia, $\mathrm{P}>0.05$ (Table 4).

\section{Discussion}

Breast cancer is a major public health problem in both developed and developing countries. Its incidence is rapidly increasing (1-3). In general, different sociodemographic and hematologic characterizations are very important and should be considered in order to maximize treatment success and patient survival. In this study, the majority, $54.3 \%$ of the study participants were less than 40 years of age. This finding is comparable with a study conducted on the prevalence of estrogen receptor-negative breast cancer patients in Ethiopia, where 35\% of the study participants were between 30-39 years old (23). On the other hand, our finding is not comparable with a study conducted in Iraq which indicated that $58.4 \%$ of the 
participants were found to be between 50 and 59 years (18). This difference could be due to lifestyle, diet, genetic, population characteristics of the countries and related factors.

Even though breast cancer occurrence is believed to be higher in above 50 years of age, in this study $r$, $15.2 \%$ of cases were found to be less than 30 years old, which is comparable with another study done in Ethiopia (23). However, this study is incomparable with a study done in India, which indicated that there is no breast cancer case in those less than 30 years of age; this difference could be due to life style, genetic factors and the population distribution of the country (19). In general, this study revealed that the majority, $76.5 \%$ of breast cancer cases were less than 50 years old. This finding is somehow comparable with study done in Pakistan, Sindh, which indicated that, $61.67 \%$ of the cases were less than 50 years (24).

Regarding educational status, majority, $43.3 \%$ of the cases were illiterate, which is lower than the study conducted in Sindh which indicated that $71.7 \%$ were illiterate; this difference could be due to smaller sample size and study setting (24). In general, large number, (34.3\%), of cases as opposed to $12.6 \%$ of the controls had a monthly income of less than 1000 Ethiopian Birr. However, based on another study, the distribution of cancer was noted to be more on socioeconomically better individuals, presumably owing to lifestyle risks they are exposed to (25). Regarding marital status, majority, $76.1 \%$ of the cases were married. That appears to be comparable with studies conducted in different countries $(6,24)$.

Hematological parameters are tests which are routinely available, cost effective, standardized and provide valuable information regarding different types of diseases, including cancer (18). In this study, the mean hemoglobin, PCV, RBCs, values were significantly lower in patients compared to controls. This finding is comparable with studies conducted in Iraq (18), Nigeria (16), Sindah (Pakistan) (24).

Since HB and PCV are used as guides to diagnose anemia and anemia is one of the major problems for most of cancer patients, those parameters are usually lower compared to healthy controls $(16,24)$. This low level of hematological parameters may be associated with bone marrow suppression or immune suppression, as a result of the cancer itself, (26). The other possible reason could be if the patient condition were on pre or post-surgery, these parameters can be significantly reduced. In addition, nutritional status and clinical conditions of patients could also play the most important role in the reduction of such values $(26,27)$. Regarding red cell indices, the mean MCV and MCHC were significantly lower among cases, whereas the $\mathrm{MCH}$ was almost similar for cases and controls. This finding is comparable with study done in Nigeria (17). With the exception of $\mathrm{MCH}$, it is also supported by a study done in India, which indicated that the overall mean $\mathrm{MCV}, \mathrm{MCH}, \mathrm{MCHC}$ of cases were lower than the controls (28).

The mean WBC value of the cases and controls was almost the same. The mean platelet count was significantly higher among patients than controls (323.4 \pm 108.1 versus $282.0 \pm 70.0)$. This finding is comparable with a similar study done in Nigeria, Lagos which revealed that mean platelet count was $291.5 \pm 103.4$ and $228.8 \pm 75.6$ for cases and controls, respectively (17). This study is also supported by a similar study conducted in India, which indicated that mean platelet count was higher among cases 
compared with controls (14). This increment could be explained by the reactive thrombocytosis among most breast cancer patients as a result of cancer induced anemia. However, this finding is incomparable with similar study conducted in Iraq which indicated that the mean platelet and, WBC counts are significantly lower in cases than in controls (18). This difference could be due to small sample size, clinical characteristics, and demographic of differences of the study participants.

Regarding differential WBC count, there was a significantly higher mean value among cases compared with the controls. In this study, the mean neutrophil and lymphocyte count was $55.2 \pm 1.9 \%$ and $29.6 \pm$ $11.2 \%$ for cases and $36.4 \pm 19.3 \%$ and $24.6 \pm 8.4 \%$ for controls, respectively. This finding is comparable with a study conducted in Nigeria, which indicated a significantly higher mean value of neutrophil and lymphocytes counts, $54.8 \pm 13.1 \%$, and $38.2 \pm 12.8 \%$ for cases versus $44.4 \pm 8.9 \%, 8.8 \pm 16.0 \%$ for controls, respectively (17). This increment could be explained by neoplasm of cancer cells.

A pretreatment anemia or lecocytosis can serve as a useful marker to predict outcome of cancer. In this study, it was observed that anemia was found in $20.4 \%$ of cases and $5.6 \%$ of controls, which is comparable with a study done in Tikur Anbessa Specialized Hospital among patients with solid tumor, where the prevalence of anemia was $23 \%$ (29). It is also similar with a study done among breast cancer patients in China, which indicated that $25.3 \%$ of patients were anemic before treatment (30).

In contrast to the current study, researchers from India reported that $60 \%$ of pre chemotherapy breast cancer patient were anemic (26). This difference could be due to smaller sample size of the later study, which were 51 cases and controls. It could be also due to the study setup, the background of the study participants, and the stage of the disease. This study also indicated that leukopenia was found in $5.7 \%$ of cases and $3.9 \%$ of controls, this nearly comparable with study done in India (31). Thrombocytosis was observed among $23.5 \%$ of the cases and $7.8 \%$ of controls. This study was nearly was nearly comparable with study done among pretreatment breast cancer patients were $18.2 \%$ of the cases were with thrombocytosis (32). This difference could be due to difference in stage of disease and the study participants.

Limitation; since this study is a hospital based study; it may not be representative for the general population. However, in the absence of sufficient data in the country, this study from the only cancer treatment center of the country during the study period highlights the situation.

\section{Conclusion And Recommendations}

The study observed that most of the study participants were young and there were significant number of breast cancer cases even under the age of 30 years. In addition, nearly half, $(43 \%)$ of breast cancer cases were illiterate, with low monthly income. Regarding hematologic profile, the mean hemoglobin, red blood cell count, packed cell volume, mean corpuscular volume; mean corpuscular hemoglobin concentration values were significantly lower among cases compared to controls. On the other hand, some hematological parameters like platelet count, neutrophil count, are significantly higher among controls. Anemia and thrombocytosis were observed as major hematologic abnormalities. 
Since younger women were highly affected by breast cancer, attention should be given by concerned bodies for young population in every aspect of prevention and control activities of cancer in general and breast cancer in particular. Since this study may not provide representative evidence, it is important to conduct further studies with large sample size in order to confirm the findings of this study and design appropriate interventions.

\section{Abbreviations}

BC: Breast cancer; CT:,Computed Tomography; HB: Hemoglobin; HRT: Hormone Replacement Therapy; $\mathrm{MCH}$ : Mean Corpuscular hemoglobin; MCHC:Mean Corpuscular Hemoglobin Concentration; MCV: Mean Corpuscular Volume; NGO: Non-Governmental Organization; PCV: Packed Cell Volume; RBC: Red Blood Cell; SPH: School of Public Health; SPSS: Statistical Package for Social Sciences; TASH: Tikur Anbessa Specialized Hospital; WBC: White Blood Cell

\section{Declarations}

\section{Ethics approval and consent to participate}

- This study was approved by Institutional Review Board of College of Health Sciences of the Addis Ababa University. Informed written consent form was signed by the participants. Confidentiality was highly maintained throughout this study.

\section{Consent for publication}

- Study participants gave their written informed consent for publication. However in this manuscript data was not presented at individual level.

\section{Availability of data and material}

The datasets generated and/or analyzed during the current study are not publicly available due to individual privacy but are available from the corresponding author on reasonable request.

\section{Conflict of Interests:}

- All authors declare that there is no conflict of interests regarding the publication of this paper.

\section{Funding}

This study was supported by Addis Ababa University and principal investigator. The university had no role in the study design, data collection and data analysis, decision to publish and manuscript preparation.

\section{Authors' Contribution:}

- I state that this research was done by all authors indicated in this article. Fatuma Hassen, Prof. FikreEnkusilassie, Dr. Aster Tesegaye and Dr, MatiwosAssefaparticipated in the design, data 
analyses, interpretation and preparation of manuscript. Ahmed Ali, Dr.Adamu Addisse and Dr.GirmaTaye also participatedin data interpretation and preparation of this manuscript. Finally, all authors critically reviewed and approved the manuscript.

\section{Acknowled1gments:}

The authors would like to thank the Addis Ababa University, School of Public Health for facilitating the overall research activity. The Department of Oncology and the study participants are gratefully acknowledged for their cooperation.

\section{References}

1. WHO, Latest global cancer data international agency on cancer. 2018; (press release No 263)

2. Ferlay J, Soerjomataram I, Ervik M, DikshitR,Eser S, Mathers C, Rebelo M, et.al. GLOBOCAN 2012, Cancer Incidence and Mortality Worldwide: 2013; 1.

3. American cancer society. Breast Cancer Overview: American Cancer Society, CDC, 2013.

4. Jemal A, Bray F, Forman D, Brien MO, Ferlay J, Center M, et.al. Cancer Burden in Africa and Opportunities for Prevention. Cancer 2012; 118 (18) 1-13.DOI: 10.1002/cncr.27410.

5. Lundqvist A, Andersson F, Ahlberg I, Nilbert A., Gerdtham U. Socioeconomic inequalities in breast cancer incidence and mortality in Europe: a systematic review and meta-analysis. The European Journal of Public Health. 2016; 26(5): 804-813.

6. Usama M. Al-Fadhli, Ameel F. Al-Shawi, Ahmed S. Al-Nuaimi. Assessment of sociodemographic characteristics in a sample of breast cancer patients in Baghdad.J Fac Med Baghdad. 2016; 58(4): 357-360

7. AlwanNA, TawfeeqFN, , and MallahNawar A.G.. Demographic and clinical profiles of female patients diagnosed with breast cancer in Iraq. J Contemp Med Sci. 2019; 5 (1): 14-19.

8. Socio-Economic and Health Access Determinants of Breast and Cervical Cancer Screening in LowIncome Countries: Analysis of the World Health Survey. PLoS ONE. 2012; 7(11): e48834. doi: 10.1371/journal.pone.0048834.

9. Ibrahim NA, Oludara MA. Socio-demographic factors and reasons associated with delay in breast cancer presentation: Lagos State University College of Medicine Ikeja-Lagos, Nigeria, The Breast, 2012; 21(3): 416-418.

10. FMOH, Ethiopian cancer society, FMOH, 2015.

11. Abate SM, Yilma Z, Assefa M, Tigeneh W. Trends of Breast Cancer in Ethiopia. Int J Cancer Res MolMech, 2016; 2(1): doi http://dx.doi. org/10.16966/2381-3318.121.

12. Tadele, N. Evaluation of Quality of Life of Adult Cancer Patients Attending TikurAnbessa Specialized Referral Hospital, Addis Ababa Ethiopia.Ethiop J Health Sci. 2015; 25(1): 53-62.

13. Federal Ministry of Health Ethiopia, Disease Prevention and Control Directorate National Cancer Control Plan 2016-2020. 2015. 
14. Varma M, Sahu A., Paneri and Kachhawa K. Study of BMI, Lipid Profile and CBC in Women having Breast Cancer, Sri Aurobindo Institute of Medical Sciences, Indore: India.Journal of Pure and Applied Microbiology.2014;8(6): 4827-4831.

15. ChenL, KongX, Yan C, Fang Y, Wang J. The research progress on the prognostic value of the common hematological parameters in peripheral venous blood in breast cancer.Oncotarges and Therapy. 2020;13: 1397-1412

16. Olufem AE, Oguntola OA, Adeoti S, Layiwola M, Akintola AA. Haematological Parameters in Female Breast Cancer Patients in South Western Nigeria. J Med Health Sci. 2013; 2(4): 398-401.

17. Akinbami A, Popoola A, Adediran A, Dosunmu A, Oshinaike O, Adebola P, et.al.Full blood count pattern of pre-chemotherapy breastcancer patients in Lagos, Nigeria.Caspian J Intern Med. 2013; 4(1): 574-579.

18. Ali L. Study effect of Breast Cancer on Some Hematological and Biochemical Parameters in Babylon Province Iraq. Journal of Pharmacy and Biological Sciences (IOSR-JPBS). 2014; 9(3):20-24.e-ISSN: 2278-3008, p-ISSN:2319-7676.

19. Al Arif AA, Kumar A,Chigurupati S, Jawed M,Pandurangan T. Petreatmentvirattions in hematological parameters of breast cancer patients. International journal ofpharmacy and pharmaceutical science. 2018; 10(2): 157-161.

20. Berhe S, Sinshaw W, Hailu M, Abebe M, Aregay A. Assessment of Knowledge of Breast Cancer and Screening Methods among Nurses in University Hospitals in Addis Ababa, Ethiopia.ISRN Oncology. 2013; V 2013: 8 pageshttp://dx.doi.org/10.1155/2013/470981.

21. Mekonen M, Ali A, Firdu N. Assessment of Breast Self-examination Practice and associated factors among women between 20 up to 70 years attending on the selected public health centers, in Addis Ababa: Addis Ababa university college of health science, school of public health Ethiopia, 2015, unpublished thesis.

22. Ethiopian cancer Association, 2007.

23. KantelhardtEJ,Assefa M, AbrhaA, Tigeneh W, Jemal A,Vetter $M$, al. The prevalence of estrogen receptor-negative breast cancer in Ethiopia. BMC Cancer. 2014; 14:895:1-

6.http://www.biomedcentral.com/1471-2407/14/895.

24. Khan S. Study of some Hematological parameters as Biomarker for breast Cancer population of Sindh.Sindh Univ. Res. Jour. (Sci. Ser.). 2017;49(1):23-

28.https://www.researchgate.net/publication/316917868.

25. Amgiasvasanth AM, Patil PS. Profile of breast cancer patients attending a tertiary care centre, Int J Community Med Public Health.2016;3(3):663-667, DOI: http://dx.doi.org/10.18203/2394040.ijcmph20160629.

26. Maccio A, Madeddu C, Gramignano G, MulasC,Tanca L,Cristina M al. The role of inflammation, iron, and nutritional status in cancer-related anemia: results of a large, prospective, observational study .haematologica 2015; 100 (1) 124 -132. 
27. Ufelle SA, UkaejiofoEO, Neboh EE, AchukwuPU, IkekpeazuEJ, Maduka IC et.al. Some hematological parameters in pre and pos surgery breast cancer patients in Enug. Nigeria, Int J Cur Bio Med. 2012; 2(1) $188-190$.

28. Smita S. Masamatti1, Vijaya C. Hematological parameters in pre chemotherapy breast cancer patients in a tertiary care centre: India, IP Journal of Diagnostic Pathology and Oncology, 201; 3 (3):237-240. DOI: 10.18231/2581-3706.2018.0049.

29. Kifle E, Hussein M, Alemu J, Tigneh W. Prevalence of anemia and associated factors among newly diagnosed patients with solid malignancy at TikurAnbessa hospital Radio therapy center: Addis Ababa Ethiopia, Advances in hematology 2019; V 2019:1 - 8. http://doi.org/10.1155/201982/79789,

30. Zhu W, Xu B. Association of Pretreatment Anemia with Pathological Response and Survival of Breast Cancer Patients Treated with Neoadjuvant Chemotherapy: A Population-Based Study:PLOSOne. 2015; 10 (8):1-13. DOI:10.1371/journal.pone.0136268.

31. BekhaTS, Bhargava S. Preoperative biochemical, hematological and radiological parameters in breast cancer, case control study.Journal of clinical and diagnostic research. 2019; 13(3): 19-23.

32. Stradimou A, loannis A. Voutsakis. Pretreatment thrombocytosis as prognostic factors in metastatic breast cancer. International journal of breast cancer. 2013; V 2013: 1-6.http: doi.org/10.1155/2013/289563.

\section{Tables}

Table 1. Sociodemographic characteristics of breast cancer cases and controls at TikurAnbessa Specialized Hospital, Addis Ababa, Ethiopia, 2019. 


\begin{tabular}{|c|c|c|c|c|}
\hline Variables & Cases & & Controls & \\
\hline Resident & Frequency & Percent & Frequency & Percent \\
\hline Urban & 163 & 70.9 & 174 & 75.7 \\
\hline Rural & 67 & 29.1 & 56 & 24.3 \\
\hline \multicolumn{5}{|l|}{ Age group (years) } \\
\hline$<40$ & 125 & 54.3 & 143 & 62.2 \\
\hline 40 and above & 105 & 45.7 & 87 & 37.8 \\
\hline \multicolumn{5}{|l|}{ Religion } \\
\hline Orthodox & 155 & 67.4 & 136 & 59.1 \\
\hline Muslim & 38 & 16.5 & 57 & 24.8 \\
\hline Protestant & 36 & 15.7 & 35 & 15.2 \\
\hline Other & 1 & 0.4 & 2 & 0.9 \\
\hline \multicolumn{5}{|l|}{ Marital status } \\
\hline Single & 23 & 10.0 & 29 & 12.6 \\
\hline Married & 175 & 76.1 & 155 & 67.4 \\
\hline Divorced/widowed & 32 & 13.9 & 46 & 20.0 \\
\hline \multicolumn{5}{|l|}{ Education level } \\
\hline Illiterate & 100 & 43.5 & 34 & 14.8 \\
\hline Read and write & 26 & 11.3 & 9 & 3.9 \\
\hline Primary education & 33 & 14.3 & 56 & 24.3 \\
\hline Secondary education & 45 & 19.6 & 69 & 30.0 \\
\hline College and University & 26 & 11.3 & 62 & 27.0 \\
\hline \multicolumn{5}{|l|}{ Occupation } \\
\hline House wife & 160 & 69.6 & 99 & 43.1 \\
\hline Government employee & 34 & 14.8 & 70 & 30.4 \\
\hline Private & 28 & 12.1 & 42 & 18.2 \\
\hline Other & 8 & 3.5 & 19 & 8.3 \\
\hline Income) & $(N=108)$ & & $(N=127)$ & \\
\hline
\end{tabular}




\begin{tabular}{|lllll|}
\hline 1000 & 37 & 34.3 & 16 & 12.6 \\
\hline $1000-2000$ & 32 & 29.6 & 37 & 29.1 \\
\hline $2001-3000$ & 10 & 9.3 & 27 & 21.3 \\
\hline Greater than 3000 & 29 & 26.9 & 47 & 37.0 \\
\hline
\end{tabular}

Table 2. HB, RBC, platelet count and PCV parameters of cases and controls at Tikur Anbessa Specialized Hospital, Addis Ababa, Ethiopia, 2019

\begin{tabular}{|c|c|c|c|}
\hline Parameter & Cases & Controls & $\begin{array}{l}\mathrm{P}- \\
\text { Value }\end{array}$ \\
\hline HB $($ Mean \pm SD) g/dl & $13.1 \pm 1.6$ & $14.0 \pm 1.3$ & 0.0001 \\
\hline Minimum $\mathrm{Hb}$ & 8.7 & 7.3 & \\
\hline Maximum Hb & 16.4 & 20.1 & \\
\hline $\mathrm{RBC}($ Mean $\pm \mathrm{SD}) \times 10^{12} / \mathrm{L}$ & $4.6 \pm 0.54$ & $4.8 \pm 0.47$ & 0.020 \\
\hline Minimum RBC & 2.84 & 3.39 & \\
\hline Maximum RBC & 6.18 & 7.12 & \\
\hline $\begin{array}{l}\text { Platelet (Mean } \pm \text { SD) } x \\
10^{9} \mathrm{~L}\end{array}$ & $\begin{array}{l}323.4 \pm \\
108.1\end{array}$ & $282.0 \pm 70.0$ & 0.0001 \\
\hline Minimum Platlet & 110.0 & 119.0 & \\
\hline Maximum Platlet & 827.0 & 469.0 & \\
\hline PCV $($ Mean \pm SD) \% & $38.7 \pm 4.5$ & $40.5 \pm 3.5$ & 0.0001 \\
\hline Minimum PCV & 26.20 & 24.80 & \\
\hline Maximum PCV & 49.20 & 58.40 & \\
\hline
\end{tabular}

$H B=$ Hemoglobin, $P C V=$ Packed cell volume, $W B C=$ White blood cell.

Table 3: Red cell indices values in breast cancer cases and controls at Tikur Anbessa Specialized Hospital, Addis Ababa, Ethiopia, 2019. 


\begin{tabular}{|llll|}
\hline Red cell indices parameters & Cases & Controls & P-value \\
\hline MCV, fl (Mean \pm SD) & $\mathbf{8 4 . 3 + 8 . 1}$ & $\mathbf{8 5 . 7 + 6 . 0}$ & $\mathbf{0 . 0 4 2}$ \\
\hline Minimum MCV & 65.6 & 62.4 & \\
\hline Maximum MCV & 105.9 & 111.5 & \\
\hline MCH, pg (Mean \pm SD) & $\mathbf{2 9 . 0 + 4 . 2}$ & $\mathbf{2 9 . 5 + 2 . 4}$ & $\mathbf{0 . 1 5 3}$ \\
\hline Minimum MCH & 21.2 & 19.3 & \\
\hline Maximum MCH & 37.5 & 39.2 & \\
\hline MCHC, gm/dl (Mean \pm SD) & $33.7+1.7$ & $34.2+2.5$ & $\mathbf{0 . 0 0 5}$ \\
\hline Minimum MCHC & 22.4 & 29.4 & \\
\hline Maximum MCHC & 38.5 & 36.6 & \\
\hline
\end{tabular}

Key $=M C V=$ Mean Cell Volume $M C H=$ Mean Cell Hemoglobin, $M C H C=$ Mean Cell Hemoglobin Concentration

Table 4: Distribution of abnormal hemoglobin, leucocyte and platelet values between breast cancer cases and controls atTikurAnbessa Specialized Hospital, Addis Ababa, Ethiopia, 2019. 


\begin{tabular}{|c|c|c|c|c|c|}
\hline \multirow{2}{*}{$\begin{array}{l}\text { Parameters } \\
\text { Hemoglobin (gm/dl) }\end{array}$} & \multicolumn{2}{|c|}{ Cases } & \multicolumn{2}{|c|}{ Controls } & $\mathrm{P}$-value \\
\hline & $\mathrm{N}$ & $\%$ & $\mathrm{~N}$ & $\%$ & \multirow{5}{*}{0.0001} \\
\hline 12 and above (No anemia) & 183 & 79.6 & 217 & 94.3 & \\
\hline Mild anemia & 20 & 8.7 & 8 & 3.5 & \\
\hline Moderate anemia & 27 & 11.7 & 4 & 1.7 & \\
\hline Severe anemia & 0 & 0 & 1 & 0.4 & \\
\hline Microcytic anemia & 64 & 28.2 & 42 & 18.4 & \multirow[b]{2}{*}{0.046} \\
\hline Macrocytic anemia & 2 & 0.9 & 3 & 1.3 & \\
\hline Hypochromic anemia & 15 & 6.6 & 8 & 3.5 & 0.134 \\
\hline Normocytic anemia & 23 & 10.0 & 7 & 3.0 & 0.003 \\
\hline Normochromic anemia & 27 & 11.7 & 9 & 3.9 & 0.002 \\
\hline Microcytic Hypochromic & 9 & 3.9 & 4 & 1.7 & 0.159 \\
\hline Leucopenia & 13 & 5.7 & 9 & 3.9 & \multirow[t]{3}{*}{0.681} \\
\hline Normal & 198 & 86.1 & 202 & 87.8 & \\
\hline Lecucytosis & 19 & 8.3 & 19 & 8.3 & \\
\hline Thrombocytopenia & 4 & 1.7 & 5 & 2.2 & \multirow{3}{*}{0.0001} \\
\hline Normal & 172 & 74.8 & 207 & 90 & \\
\hline Thrombocytosis & 54 & 23.5 & 18 & 7.8 & \\
\hline Both anemic and thrombocytosis & 16 & 7.0 & 1 & 0.4 & 0.0001 \\
\hline Both anemic, thrombocytosis and lecucytosis & 5 & 2.2 & 0 & 0.0 & 0.025 \\
\hline
\end{tabular}

*The reference range is based on the WHO classification of anemia. Regarding leucocyte and platelet, the reference range is based on the established range of the CBC Sysmex $\mathrm{KX}-21 \mathrm{~N}$ hematology analyzer

*Anemia, When HB<12gm/dl, (Mild anemia when HB is 10.9-11.0 gm/dl, Moderate anemia when HB is 8.0-10.9 gm/dl, and Severe anemia when $H B$ is $<8 \mathrm{gm} / \mathrm{dl}$ )

* Lecucytosis: when total WBC count is $>10.4 \times 10^{9} / L$, Leucopenia: when total WBC count is $<3.7 \times 10^{9} / L$ *Thrombocytopenia: when total plateletcount is $<140 \times 10^{9} / \mathrm{L}$, Thrombocytosis: when total platelet count is $385 \times 10^{9} / \mathrm{L}$

*Microcytic anemia: MCV< 82fl, Macrocytic anemia: MCV > 99fl, Hypochromic anemia: MCHC: $<32$ $m g / d l$ 
Figures

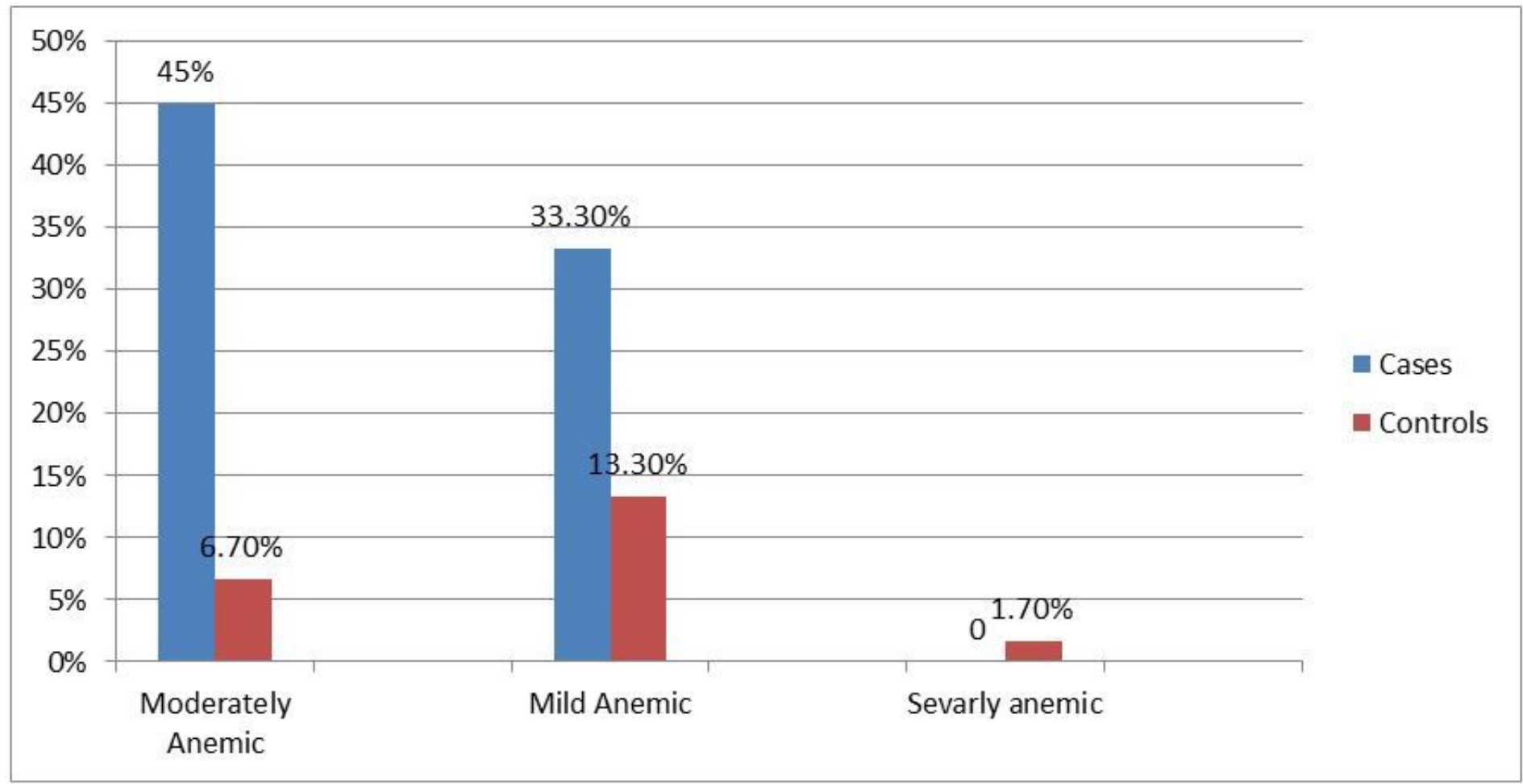

*Classification of Anemia: When $\mathrm{HB}<12 \mathrm{gm} / \mathrm{dl}$, (Mild anemia when $\mathrm{HB}$ is 10.9-11.0 gm/dl, Moderate anemia when $\mathrm{HB}$ is 8.0$10.9 \mathrm{gm} / \mathrm{dl}$, and Severe anemia when $\mathrm{HB}$ is $<8 \mathrm{gm} / \mathrm{dl}$ )

\section{Figure 1}

Severity of of anemia among breast cancer cases and controls at Tikur Anbessa Specialized Hospital, Addis Ababa, 2019. $(\mathrm{n}=60)$

\section{Supplementary Files}

This is a list of supplementary files associated with this preprint. Click to download.

- Datacollectiontool.docx 